\title{
Inhaler Refill Dosing Unit
}

National Cancer Institute

\section{Source}

National Cancer Institute. Inhaler Refill Dosing Unit. NCI Thesaurus. Code C62418.

A dosing unit equal to the amount of active ing redient(s) contained in an inhaler refill. 